\title{
Freddy Timmermann
}

El gran terror. Miedo, emoción y discurso. Chile, 1973-1980

\section{Santiago de Chile, Ediciones Copygraph, 2015, 337 pp. ISBN 978956119707}

En esta obra, Freddy Timmermann estudia el miedo administrado por la dictadura de Pinochet en su primera fase (1973-1980). ¿Qué es lo que lo hace centrarse en este fenómeno? Según mi lectura hay aquí una reacción a las explicaciones estructurales, en términos de la economía y la política internacional, como a los excesos funcionalistas en términos de la dinámica que adquirió el sistema de partidos políticos a fines de los 60 e inicios de los 70 . El miedo, como un fenómeno social, experimentado tanto por "los de abajo" como por "los de arriba", fruto de la creciente conflictividad social, reavivó viejos fantasmas de la historia de Chile y está dentro de los motivos internos más determinantes para comprender el acaecimiento del Golpe de Estado. La dictadura administró de manera consciente este miedo y lo amplificó instaurando un terrorismo de Estado: "El 5 de junio el presidente de la Junta de Gobierno, Augusto Pinochet, le envía el Memorandum Nº 229 al Secretario General de Gobierno en que le solicita "disponer la elaboración de un Plan de Acción Psicológica para lo que resta del año 1974” (p. 127).

Como lo anuncia su autor, este trabajo constituye al miedo como objeto historiográfico, para lo cual se centra -únicamente- en el análisis de documentos oficiales emitidos por "la Junta", tales como los Bandos, el Acta de constitución de la Junta, la Declaración de Principios y el Discurso de Chacarillas, entre los más relevantes. Aquí, una primera pregunta: ¿Es del todo pertinente el puro análisis documental para dar cuenta de una emoción? Yo creo que sirve, indudablemente, pero no basta. Y esto por la característica del "objeto".

En materia de conocimiento del rol jugado en cierto contexto por una emoción como el miedo, me parece que al registro explicativo ha de agregarse la vía emocional misma. Se trata del acceso a una experiencia. Y si bien por principio la experiencia es intransferible en toda su intensidad mediante mecanismos explicativos y formatos de representación tradicionales, sí que puede ser "suscitada" en otro espíritu. Mi referencia es un tanto esotérica, pienso en el libro Lo Santo de Rudolf Otto. Como se recordará, esta obra intentaba, por la vía fenomenológica, un conocimiento de la experiencia de lo sagrado. El modo de hacerlo requería primero una cuota mínima de experiencias de diverso tipo por parte de los lectores; si estos no la tenían debían renunciar a seguir la lectura del libro, pues en lo que venía trataba de que en la memoria emotiva de los lectores revitalizan experiencias de distinto tipo, para que en suma diera un análogo a la experiencia de lo sagrado. Es una forma posible. (Aunque quizá cada vez menos posible en un mundo en que experiencias de cierto tipo se van perdiendo inexorablemente y con ellas la posibilidad de comprensión, no solo del pasado, sino de cualquier Otro).

Entonces hay aquí una reacción en contra de la falta de alcance de los tradicionales enfoques para dar cuenta de toda la complejidad de un fenómeno. Pero hay más a mi modo de ver: como nunca el presente determina al historiador.

Pese a los fenómenos de superficie, Timmermann sabe que Chile sigue siendo un país cuya realidad política se explica en gran medida por la repartición de sus miedos. Lo señalo, porque a partir de las protestas estudiantiles del 2011, mal identificadas como “movimiento social del 2011”, surgió una explicación estándar que terminó por instalarse como lugar común: "se trata de una generación que no tiene miedo, son jóvenes nacidos en 
democracia". (Extraño juicio viniendo de una izquierda que ha insistido que esta democracia no es realmente democracia).

Si hay algo que Timmermann establece desde el comienzo es que el miedo es un elemento constituyente de la política, no su excepción, lo es así desde que desapareció la polis, afirma con Castoriadis. Pero aquí hay diferencias de intensidades, pues los miedos e inseguridades de un país reconstruido en la ortodoxia neoliberal quizá sean de los peores del mundo, no por el grado de dolor o sufrimiento físico, sino por instalar dispositivos psicopolíticos "en" los sujetos. No necesitamos la dictadura, porque la tenemos ahora dentro: la autocensura, la autoexplotación, el hiperconsumo y su lógica proyectada a todos los niveles de la vida, y sobre todo la soledad enmascarada en el acceso ilimitado a "la red". Son realidades que todavía están por ser estudiadas en Chile. (Algo de esto ha adelantado de modo general Byung-Chul Han) ${ }^{1}$.

Pues bien, al confrontarnos con ese otro miedo del pasado, Timmermann cumple un requisito propio de lo que Michel de Certeau definió como "la operación historiográfica"2: propiciar ese movimiento entre empatía y extrañamiento (continuidad y ruptura) de nosotros respecto de esos otros del pasado. "Ese era el miedo en Chile cuarenta años atrás. Si el miedo es constituyente de la política y no su excepción ¿Cuál y cómo es entonces nuestro miedo? ¿Ante qué cosas y situaciones lo experimentamos? ¿Qué rasgo nuestro puede explicar?”:“Un grupo, ya se sabe, no puede expresar lo que tiene ante sí -lo que aún falta- más que por una redistribución de su pasado"3.

Existen al menos dos vías por las que el historiador define sus problemas de estudio, que por economía de exposición llamaremos "cientificista" una, y "ciudadana" la otra. La primera se justifica en el desarrollo previo de un campo de investigación, detectando "lagunas" de saber que la nueva investigación debe completar. La "utilidad para la vida", parafraseando a Nietzsche, de este tipo de investigación es incierta. Lo que sí es claro es que es el modo más seguro de construir una carrera académica.

La otra, la ciudadana, requiere de una suerte de "doble conexión" de parte del historiador: con el desarrollo de la producción historiográfica de su área de especialidad y con las encrucijadas y dilemas que le son contemporáneas y propias. Pues el historiador es un sujeto que estudia el acontecer estando siempre él mismo aconteciendo. Esta condición ontológica del historiador se asume o se enmascara, no hay más que estas dos alternativas.

Si no queremos seguir hablando solos, o entre nosotros mismos, debiéramos atender la indicación de Enzo Traverso: "para escribir un libro de Historia que no sea sólo un trabajo aislado de erudición, hace falta también una demanda social, pública" ${ }^{4}$. Esto, de algún modo, equivale a rehabilitar, para el historiador, la función clásica del filósofo: responder las preguntas que se hace una sociedad, pero cuando esta no se las hace debe interrogarla

1 Han, Byung-Chul, Psicopolítica. Neoliberalismo y nuevas técnicas de poder, Barcelona, Herder, 2014.

2 De Certeau, Michel, La escritura de la historia, México, Universidad Iberoamericana, 2006.

3 Op. cit., p. 53.

4 Traverso, Enzo, El pasado, instrucciones de uso. Historia, memoria, política, Madrid, Marcial Pons, 2007, p. 40. 
de modo impertinente. Desde luego los riesgos aquí se multiplican. Sabemos el destino de Sócrates por usar la pregunta filosófica para propiciar la virtud pública. Para el historiador de hoy esos peligros solo se han de soslayar imponiéndose rigor investigativo y elegancia de los planteamientos y provocaciones. Son precisamente estos los atributos de los trabajos que Freddy Timmermann ha dedicado a la historia contemporánea de Chile.

Pablo Aravena NúÑEZ Universidad de Valparaíso 